\title{
ANALISIS PERSEDIAAN BAHAN BAKU PADA USAHA KECIL MENENGAH PRODUK ROTI (STUDI KASUS UD NABILA DESA KALASEY, KECAMATAN MANDOLANG)
}

\author{
Sheila Giltania Kaluntas \\ Noortje M. Benu \\ Yolanda P. I. Rori
}

\begin{abstract}
The aimed of the study to analyzed the supply of raw material of bread at UD Nabila more specifically the raw material of the flour, sugar, butter and eggs. This study was conducted for two months, since January 2016 until February 2016. The data used in this research are secondary data, the data obtained from UD Nabila and primary data by interviews to the owner of UD Nabila. The analysis used in this research used EOQ (Economic Order Quantity) to know when to make a reservation and determine amount to reserve. Based on the results of this research at UD Nabila, it can be concluded that in determining the purchase of a raw material UD Nabila, don't have the good inventory management of raw recipes. UD Nabila has not been able to calculate the optimal purchase of raw material, which is the purchase of raw material UD Nabila is more than the use of raw recipes, it causing profuse costs. $* l^{*}$
\end{abstract}

Keywords: supply analyzing, raw material of bread, UD Nabila, Kalasey Village, Minahasa

\begin{abstract}
ABSTRAK
Penelitian ini bertujuan untuk menganalisis persediaan bahan baku roti Pada UD Nabila lebih khusus untuk bahan baku tepung, gula, mentega dan telur. Penelitian ini dilaksanakan selama dua bulan, sejak bulan Januari sampai bulan Februari 2016. Data yang digunakan dalam penelitian ini adalah data sekunder yaitu data-data yang diperoleh dari UD Nabila dan data primer yaitu data yang diambil melalui wawancara langsung kepada pemilik UD Nabila. Analisis data yang digunakan dalam penelitian ini adalah dengan menggunakan metode EOQ (Econimic Order Quantity) untuk mengetahui kapan melakukan pemesanan kembali dan menentukan berapa jumlah yang dipesan. Berdasarkan hasil penelitian yang dilaksanakan di UD Nabila, dapat di simpulkan bahwa dalam menetapkan pembelian bahan baku UD Nabila, belum mempunyai manajemen persediaan bahan baku. UD Nabila belum dapat memperhitungkan pembelian bahan baku yang optimal, dimana pembelian bahan baku UD Nabila lebih besar dibandingkan dengan penggunaan bahan baku yang mengakibatkan terjadinya pemborosan biaya.
\end{abstract}

Kata kunci: analisis persediaan, bahan baku roti, UD Nabila, Kalasey Village, Minahasa

\section{PENDAHULUAN}

\section{Latar belakang}

Dalam perkembangan ekonomi di era sekarang ini, usaha-usaha yang ada di Indonesia berkembang dengan sangat pesat. Perkembangan yang terjadi ini menyebabkan produkproduk yang ada saling bersaing antara satu dengan yang lain, khususnya bagi produkproduk sejenis. Untuk itu pengusaha harus bekerja lebih efisien dalam menghadapi persaingan demi menjaga kelangsungan operasi.

Kelangsungan operasi dipengaruhi oleh ada atau tidaknya bahan baku yang akan diolah dalam produksi (Ruauw, 2011) untuk itu perlu adanya persediaan yang dilakukan oleh pengusaha. Namun persediaan merupakan salah satu masalah yang dihadapi manajemen suatu usaha, dimana pembelian bahan baku yang tidak optimal akan berakibat tidak baik terhadap kelancaran operasi. Jika persediaan bahan baku 
yang terlalu banyak atau terlalu besar akan mengakibatkan biaya penyimpanan dari pada bahan baku akan menjadi tinggi dan berkurangnya dana untuk investasi dalam bidang lain. Sebaliknya persediaan bahan baku yang terlalu sedikit atau terlalu kecil akan mempengaruhi kelancaran produksi suatu usaha dimana usaha tersebut akan kekurangan pesediaan bahan baku.

Ketersediaan bahan baku yang kontinu juga merupakan masalah yang dihadapi suatu usaha. Dimana biasanya bahan baku yang digunakan, seringkali tidak tersedia. Tidak tersedianya bahan baku tersebut dapat disebabkan karena faktor musim, atau karena kendala faktor ekonomi misalnya harga bahan baku yang digunakan, menurun sehingga petani tidak memproduksi bahan tersebut atau juga dapat disebabkan karena berubahnya kebijakan dari pemerintah (Soekartawi, 2005)

UD Nabila merupakan usaha kecil menengah yang bergerak di industri pengolahan. UD Nabila ini terletak di Desa Kalasey Satu Kecamatan Mandolang Kabupaten Minahasa. Usaha ini berdiri pada tahun 2003. Usaha ini memiliki jumlah tenaga kerja sebanyak 8 orang. Pemasaran produk roti ini dilakukan dengan sistem retail (secara Langsung dari UD Nabila langsung kepada konsumen) dan sisitem dealer (penjualan dari UD Nabila ke pengecer kemudian ke konsumen akhir).

Pada saat ini indutri kecil menengah lebih khusus UD Nabila belum menerapkan manajemen persediaan bahan baku yang optimal. Dimana, dalam melakukan produksi UD Nabila sering terjadi kelebihan bahan baku, terlebih khusus untuk bahan baku utama yaitu tepung, gula, mentega dan telur. Kelebihan bahan baku ini menyebabkan terjadinya pemborosan biaya pada UD Nabila. Ini merupakan masalah bagi usaha tersebut, karena tanpa adanya manajemen persediaan yang optimal UD Nabila tidak dapat menekan terjadinya pemborosan biaya dan dapat menyebabkan kegiatan produksi usaha tersebut akan terhambat.

Pada Penelitian ini akan digunakan metode persediaan dengan model EOQ (Economi Order Quantity). Kerena model EOQ (Economi Order Quantity) dapat menjawab pertanyaan berapa jumlah yang harus dipesan dan kapan melakukan pemesanan kembali, sehingga UD Nabila dapat meminimalisasi terjadinya kekurangan bahan baku yang dapat menyebabkan produksi tidak berjalan dengan lancar dan tidak dapat memenuhi keinginan pelanggan. Selain itu juga model EOQ (Economi Order Quantity) dapat menekan biaya-biaya penyimpanan yang ada.

\section{Rumusan Masalah}

Berdasarkan latar belakang, maka yang menjadi rumusan masalah dalam penelitian ini adalah bagaimana persediaan bahan baku roti pada UD Nabila, lebih khusus untuk bahan baku tepung, gula, mentega dan telur.

\section{Tujuan Penelitian}

Penelitian ini bertujuan untuk menganalisis persediaan bahan baku roti Pada UD Nabila lebih untuk bahan baku tepung, gula, mentega dan telur.

\section{Manfaat Penelitian}

Manfaat dari penelitian ini adalah memberikan informasi serta masukan baik kepada pemilik usaha maupun kepada pembaca bagaimana mengambil keputusan berkaitan dengan persediaan bahan baku.

\section{METODOLOGI PENELITIAN}

\section{Waktu dan Tempat Penelitian}

Penelitian ini dilaksanakan pada UD Nabila yang bertempat di Desa Kalasey 1 Kecamatan Mandolang Kabupaten Minahasa. Penelitian ini berlangsung selama \pm 2 bulan (mulai dari bulan Januari 2016 sampai dengan bulan februari 2016).

\section{Metode Pengumpulan Data}

Data yang digunakan dalam penelitian ini adalah data primer dan data sekunder. Data primer diperoleh melalui wawancara langsung kepada pemilik usaha dengan menggunakan daftar pertanyaan dalam bentuk kuisioner, sedangkan data sekunder diperoleh dari UD Nabila.

\section{Konsep Pengukuran Variabel}

Variabel-variabel yang digunakan dalam penelitian ini adalah : 
a. Penentuan Jumlah Pesanan Ekonomis (Economic Order Quantity), kuantitas bahan yang dibeli pada setiap kali pembelian dengan biaya yang paling minimal $(\mathrm{Kg})$.

b. Biaya-Biaya Persediaan, yaitu biaya-biaya untuk menyelengarakan persediaan bahan baku. Biaya-biaya ini terdiri atas:

1. Biaya Penyimpanan Total (Carryng Cost), yaitu biaya yang dikeluarkan untuk menyimpan bahan baku tersebut (Rp).

2. Biaya Pemesanan Total (Ordering Cost), yaitu biaya yang dikeluarkan untuk memesan bahan baku yang akan digunakan (Rp).

c. Biaya Total Persediaan (Total Inventory Cost), merupakan penjumlahan total biaya pemesanan dan total biaya penyimpanan bahan baku (Rp).

d. persediaan pengaman (Safety stok) merupakan persediaan tambahan yang diadakan untuk melindungi atau menjaga kemungkinan terjadinya kekurangan bahan baku (stock out) (Kg).

e. Pemesanan Ulang (Reorder point), saat atau waktu tertentu perusahaan harus mengadakan pemesanan bahan dasar kembali, sehingga datangnya pesanan tersebut tepat dengan habisnya bahan dasar yang dibeli $(\mathrm{Kg})$.

f. Persediaan Maksimum (Maximum Inventory) diperlukan oleh perusahaan agar kuantitas persediaan yang ada di gudang tidak berlebihan sehingga tidak terjadi pemborosan modal kerja $(\mathrm{Kg})$.

\section{Metode Analisis Data}

Analisis data yang digunakan dalam penelitian ini adalah menggunakan metode dengan rumus Economic Order Quantity (EOQ) :

Keterangan :

$$
\mathrm{EOQ}=\sqrt{\frac{2 S D}{H}}
$$

S: Biaya Pemesanan (fixed ordering cost) (Rp).

D: Penggunaan atau permintaan yang diperkirakan per periode waktu $(\mathrm{Kg})$

$\mathrm{H}$ : Biaya Penyimpanan (carrying cost) (Rp)

1. Frekuensi Pembelian

$$
\mathbf{F}=\frac{D}{Q}
$$

Keterangan :

D: Penggunaan atau permintaan yang diperkirakan per periode waktu(Kg)

$\mathrm{Q}^{*}$ : Kuantitas pemesanan optimum = EOQ $(\mathrm{Kg})$

2. Daur Pemesanan Ulang

$$
\frac{\text { Jumlah Hari Kerja }}{F}
$$

Keterangan :

F: Frekuensi Pembelian (Hari)

3. Biaya Total Persediaan (Total Inventory Cost)

$$
\mathrm{TIC}=\frac{D}{Q *} S+\frac{Q^{*}}{2} H
$$

Keterangan :

D: Penggunaan atau permintaan yang diperkirakan per periode waktu $(\mathrm{Kg})$

$\mathrm{S}$ : Biaya Pemesanan (fixed ordering cost) (Rp)

$\mathrm{Q}^{*}: \quad$ Kuantitas pemesanan optimum $=\mathrm{EOQ}$ $(\mathrm{Kg})$

$\mathrm{H}$ : Biaya Penyimpanan (carrying cost) (Rp)

4. Persediaan Pengaman (safety stok)

$$
\begin{array}{ll}
\text { Safety } & \text { stok }=Z q \\
\mathrm{Z} & : \text { standar Deviasi } \\
\mathrm{q} & : \sqrt{\frac{(€ X-Y) 2}{n}}
\end{array}
$$

Keterangan :

q: Kuadrat eror

$\mathrm{X}$ : penggunaan bahan baku senyataanya $(\mathrm{Kg})$

$\mathrm{Y}$ : perkiraan penggunaan bahan baku $(\mathrm{Kg})$

5. Pemesanan Kembali :

Penentuan Pemesanan Kembali

$$
\mathrm{ROP}=\text { safety stock }+(\text { Lead Time } x Q)
$$

Keterangan :

ROP :reorder point

Lead Time : Waktu tunggu (hari)

Q : Penggunaan bahan baku ratarata per hari $(\mathrm{Kg})$

6. Persediaan Maksimum (Maximum Inventory) Maximum Inventory $=$ safety stock + EOQ 


\section{HASIL DAN PEMBAHASAN}

\section{Profil Usaha}

UD Nabila merupakan usaha kecil menengah yang bergerak di industri pengolahan. Usaha ini didirikan pada tahun 2003 oleh Bapak Arifuddin. UD Nabila terletak di Desa Kalasey Satu Kecamatan Mandolang Kabupaten Minahasa. Usaha ini memiliki jumlah tenaga kerja sebanyak 8 orang dengan upah Rp. 1.500.000/org. Hari kerja UD Nabila dimulai dari Senin-Jumat dengan jam kerja 09.00 sampai 18.00. Dalam satu hari UD Nabila dapat memproduksi 300 buah roti kasur, 200 buah roti tawar dan 1000 buah roti kecil. Daerah pemasaran UD Nabila sudah cukup luas, yaitu didaerah Manado, Minahasa, Minahasa Selatan, Minahasa Utara, Minahasa Tenggara dan Kotamobagu. Pemasaran produk roti ini dilakukan dengan sistem retail (Secara Langsung dari UD Nabila langsung kepada konsumen) dan sistem dealer ( penjualan dari UD Nabila ke pengecer kemudian ke konsumen akhir).

Usaha ini memproduksi bermacammacam roti, Seperti roti tawar, roti kasur, Roti Kecil (roti coklat, roti keju, roti coklat keju) Roti Special dan Roti kering. UD Nabila menjual dengan menggunakan dua harga yaitu harga yang di jual langsung ke konsumen dan harga dari UD Nabila ke pengecer kemudian ke konsumen akhir. Di bawah ini akan disajikan daftar harga untuk masing-masing produk roti.

\section{Tabel 1. Daftar Harga Roti UD Nabila}

\begin{tabular}{ll}
\hline \multicolumn{1}{c}{ Sistem Retail } & \multicolumn{1}{c}{ Sistem Dealer } \\
\hline Roti kecil Rp.3000 & Roti kecil Rp. 2500 \\
Roti Tawar Rp.8000 & Roti Tawar Rp.7000 \\
Roti Special Rp.4000 & Roti Special Rp.3500 \\
Roti Kasur Rp.7000 & Roti Kasur Rp.6000 \\
Roti Kering Rp.7000 & Roti Kering Rp.6000 \\
\hline
\end{tabular}

Sumber: Data Primer (diolah),2016

\section{Jenis dan Kapasitas Alat}

Jenis alat yang digunakan dalam produksi roti UD Nabila antara lain :
1. Oven

Oven adalah alat yang berfungsi untuk mengeringkan dan memanaskan bahan makanan. kapasitas oven untuk satu kali proses adalah 60 buah roti besar/jam dan 120 buah roti kecil/jam. Jumlah oven yang dimiliki oleh UD Nabila sebanyak 5 unit.

2. Mixer

Mixer adalah alat yang berfungsi untuk mengaduk dan mencampur bahan baku yang akan di olah. Kapasitas mixer untuk satu kali proses adalah 20 $\mathrm{Kg}$ /jam. Jumlah mixer yang dimiliki UD Nabila sebanyak 2 unit.

3. Timbangan

Timbang di gunakan agar roti yang akan diproduksi memiliki jumlah dan berat yang sama. Jumlah timbangan yang dimiliki UD Nabila Sebanyak 1 unit.

4. Mesin Pengaduk keju dan coklat

Mesin ini di gunakan untuk menghaluskan keju dan coklat yang akan digunakan. Kapasita mesin ini untuk satu kali proses adalah $3 \mathrm{Kg} / 15$ menit. Jumlah alat yang digunakan sebanyak 1 buah.

5. Mesin Pencetak roti

Mesin pencetak roti digunakan agar roti yang di hasilkan memiliki bentuk yang sama. Kapasitas mesin pencetak roti untuk satu kali proses adalah 30 buah. Jumlah alat yang dimiliki sebanyak 1 unit.

\section{Rantai Produksi UD Nabila}

Kegiatan produksi UD Nabila dimulai dari pengadaan bahan baku, peyiapan bahan, pengolahan, percetakan, pengeringan/ pembakaran dengan oven, pendinginan, kemas dan kemudian menghasilkan roti yang siap di pasarkan.

\section{Struktur Organisasi}

Struktur organisasi disusun agar proses kegiatan suatu usaha dapat berjalan dengan lancar dan dapat mencapai tujuan dari usaha tersebut . Berikut ini struktur organisasi dari UD Nabila. 


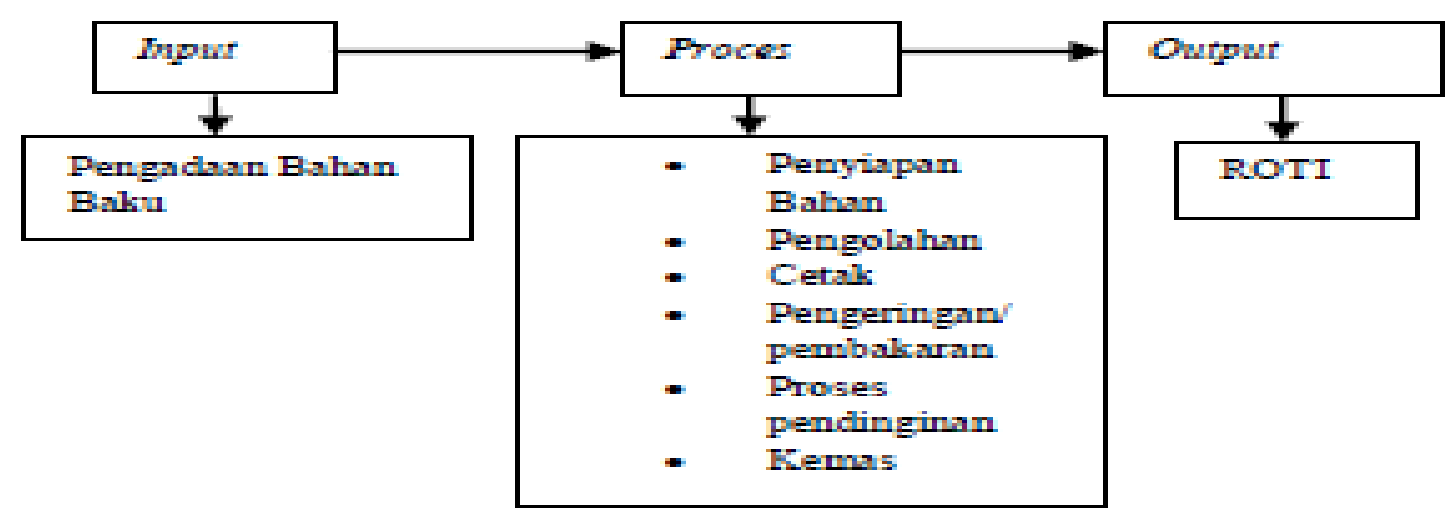

\section{Gambar 1. Rantai Produksi UD Nabila}

Tugas dan tanggung jawab ini dilakukan secara bersama oleh pemilik UD Nabila dengan kedelapan tenaga kerja yang ada. Tugas-tugas tersebut, yaitu :

1. Keuangan dan Administrasi

Bertugas untuk menyiapkan barang yang akan digunakan dalam proses produksi, membuat pembukuan tentang pengeluaran dan pemasukan setiap hari, mencatat semua hasil kegiatan produksi dan mencatat kehadiran dari tenaga kerja yang ada.

2. Pemasaran

Bertugas untuk memasarkan produk roti. Mulai dari pengiriman barang sampai ke tangan konsumen akhir.

3. Produksi

Bertugas untuk mengerjakan dan menyelesaikan proses pembuatan roti sampai di kemas dengan kuantitas dan kualitas barang yang baik.

\section{Legalitas Perusahaan}

UD Nabila Merupakan usaha Kecil menengah yang sudah berbadan hukum, berikut ini dokumen-dokumen yang dimiliki oleh UD Nabila.

1. Surat Isin Usaha Perdagangan Kecil

Nomor : :1.06/1072/SIUP//PK/V/2013

Nama Perusahaan: Nabila

Merek : Milik Sendiri

Nama : Arifuddin

Modal dan Kekayaan bersih : Rp. 300.000.000

Kegiatan Usaha : Produsen, penyalur

Bidang Usaha : Industri Kecil

Jenis Barang atau Jasa : Roti

2. Nomor pokok Wajib Pajak

Nomor : :54.429.795.5-823.000
Nama : Arifuddin

Alamat : Jaga V Kalasey 1 Minahasa

3. Rekomendasi Kesehatan

Nomor : II.03/12/V/2013

Nama Perusahaan : Nabila

Jenis Usaha : Industri Roti

Alamat : Jaga V Kalasey 1 Minahasa

\section{Analisis Persediaan Bahan Baku Metode EOQ}

1. Pembelian dan Penggunaan Bahan Baku

UD Nabila melakukan pembelian bahan baku satu bulan sekali. Untuk bahan baku tepung dan gula UD Nabila memesan dari PT. Adikarya, untuk bahan baku mentega UD Nabila memesan dari PT. Mitra Kencana, dan untuk bahan baku telur UD Nabila memesan dari UD Unggas Jaya .

Berdasarkan lampiran 1 dapat disimpulkan bahwa pembelian bahan baku tepung, gula, mentega dan telur lebih besar dari pada penggunaan bahan baku pada tahun 2015, sehingga menyebabkan UD Nabila terjadi pemborosan biaya. Berikut ini jumlah Pembelian dan jumlah penggunaan bahan baku pada tahun 2015, dan pembelian, penggunaan rata-rata pada tahun 2015 :

a. Pembelian bahan baku tepung pada tahun 2015 sebanyak $29.188 \mathrm{Kg}$ dan pembelian rata-rata bahan baku tepung adalah 2.432,33 Kg. sedangkan penggunaan bahan baku tepung pada tahun 2015 sebanyak $29.152 \mathrm{Kg}$ dan 
penggunaan rata-rata adalah $2.429,33$ $\mathrm{Kg}$.

b. Pembelian bahan baku gula pada tahun 2015 sebanyak $5.825 \mathrm{Kg}$ dan pembelian rata-rata bahan baku tepung adalah 485,42 Kg. sedangkan penggunaan bahan baku tepung pada tahun 2015 sebanyak 5.804,5 $\mathrm{Kg}$ dan penggunaan rata-rata adalah $483,71 \mathrm{Kg}$.

c. Pembelian bahan baku mentega pada tahun 2015 sebanyak $3.509 \mathrm{Kg}$ dan pembelian rata-rata bahan baku tepung adalah 292,42 Kg. sedangkan penggunaan bahan baku tepung pada tahun 2015 sebanyak $3.492 \mathrm{Kg}$ dan penggunaan rata-rata adalah $291 \mathrm{Kg}$.

d. Pembelian bahan baku telur pada tahun 2015 sebanyak $1.738 \mathrm{Kg}$ dan pembelian rata-rata bahan baku tepung adalah $144,83 \mathrm{Kg}$. sedangkan penggunaan bahan baku tepung pada tahun 2015 sebanyak $1.730 \mathrm{Kg}$ dan penggunaan rata-rata adalah $144,17 \mathrm{Kg}$.

\section{Biaya Pemesanan}

Biaya pemesanan adalah biaya yang dikeluarkan setiap kali melakukan pemesanan. Biaya pemesanan pada UD Nabila terdiri dari biaya telepon. Biaya telpon yaitu biaya yang timbul karena adanya komunikasi pemesanan bahan baku dengan para distributor atau supplier. Biaya telepon ini berupa biaya pulsa.

Total biaya pemesanan bahan baku pada UD Nabila pada tahun 2015 berjumlah Rp.200.000. Biaya pemesanan setiap kali pesan dapat di peroleh dengan cara perhitungan jumlah total biaya pemesanan Rp.200.000 dibagi dengan 12 bulan ( $12 \mathrm{kali}$ melakukan pemesanan) maka di dapat Rp. 16.666,67 setiap kali melakukan pemesanan untuk masing-masing bahan baku.

\section{Biaya Penyimpanan}

Biaya penyimpanan merupakan biaya yang dikeluarkan untuk menyimpan bahan baku. Biaya penyimpanan pada UD Nabila terdiri dari Biaya penerangan. Biaya penerangan yaitu biaya yang dikeluarkan untuk menerangi bahan baku yang telah disimpan.

Total biaya penyimpanan bahan baku pada UD Nabila tahun 2015 berjumlah Rp.1.200.000. Biaya penyimpanan yang dikeluarkan UD Nabila dapat dihitung dengan cara total biaya penyimpanan dibagi dengan nilai rata-rata pemesanan bahan baku. Jadi dapat dilihat dibawah ini biaya penyimpanan untuk masing-masing bahan baku adalah:

a. Biaya penyimpanan bahan baku tepung yang di keluarkan UD roti Nabila pada tahun 2015 adalah Rp. 493,35/Kg.

b. Biaya penyimpanan bahan baku gula yang di keluarkan UD roti Nabila pada tahun 2015 adalah Rp. 2.472,08/ Kg.

c. Biaya penyimpanan bahan baku mentega yang di keluarkan UD roti Nabila pada tahun 2015 adalah Rp. 4.103,68/ Kg.

d. Biaya penyimpanan bahan baku telur yang di keluarkan UD roti Nabila pada tahun 2015 dapat dihitung adalah Rp. 8.285,57/ $\mathrm{Kg}$.

\section{Gambar 2. Struktur Organisasi UD Nabila}




\section{Tabel 2. Penggunaan Bahan Baku, Harga per unit, Total Biaya Penggunaan, Biaya Pemesanan dan Biaya Penyimpanan tahun 2015}

\begin{tabular}{|c|c|c|c|c|c|}
\hline Bahan baku & $\begin{array}{c}\text { Jumlah } \\
\text { bahan baku }(\mathrm{Kg})\end{array}$ & $\begin{array}{c}\text { Harga } \\
\text { Bahan Baku (Rp) }\end{array}$ & $\begin{array}{l}\text { Biaya } \\
\text { Total } \\
\text { (Rp) }\end{array}$ & $\begin{array}{c}\text { Biaya } \\
\text { Pemesanan (Rp) }\end{array}$ & $\begin{array}{c}\text { Biaya } \\
\text { Penyimpanan (Rp) }\end{array}$ \\
\hline Tepung & 29.152 & 7.600 & 221.555 .200 & $16.666,67$ & 493,35 \\
\hline Gula & $5.804,5$ & 12.000 & 69.654 .000 & $16.666,67$ & $2.472,08$ \\
\hline Mentega & 3.492 & 15.000 & 52.380 .000 & $16.666,67$ & $4.103,68$ \\
\hline Telur & 1.724 & 31.500 & 54.306 .000 & $16.666,67$ & $8.285,57$ \\
\hline
\end{tabular}

Sumber: Data Primer (diolah),2016

\section{Perhitungan EOQ (Economic Order Quantity)}

Penggunaan metode EOQ bertujuan untuk menjawab pertanyaan kapan melakukan pemesanan kembali, dan berapa jumlah yang dipesan. Di bawah ini akan disajikan jumlah nilai rata-rata penggunaan bahan baku tepung, gula, mentega dan telur, harga bahan baku, besarnya biaya pemesanan, dan besarnya biaya penyimpanan tahun 2015 pada UD Nabila.

Berdasarkan Tabel 2 dapat dihitung kuantitas pembelian optimal dengan rumus :

$$
\mathrm{EOQ}=\sqrt{\frac{2 S D}{H}}
$$

Berdasarkan hasil perhitungan yang ada pada lampiran 2 menunjukan jumlah pembelian bahan baku optimal setiap kali melakukan pemesanan adalah

1. Pembelian tepung yang optimal sebesar $1.403,44 \mathrm{Kg}$. Dengan frekuensi pembelian 21 kali, daur pesan ulang selama 12 hari dan biaya total persedian Rp. 692.390,59. Hasil tersebut dapat diartikan bahwa UD Nabila dapat melakukan pemesanan sebanyak 21 kali dalam setahun dengan kuantitas pembelian optimal sebanyak 1.403,44 Kg setiap kali melakukan pemesanan dengan daur pemesanan ulang selama 12 hari dan biaya total persediaan sebanyak Rp. 692.390,59.
2. pembelian gula yang optimal adalah 279,76 Kg. Dengan frekuensi pembelian 21 kali, daur pesan ulang selama 12 hari dan biaya total persedian Rp. 691.596,97. Hasil tersebut dapat diartikan bahwa UD Nabila dapat melakukan pemesanan sebanyak 21 kali dalam setahun dengan kuantitas pembelian optimal sebanyak 276,74 Kg setiap kali melakukan pemesanan dengan daur pemesanan ulang selama 12 hari dan biaya total persediaan sebanyak $\mathrm{Rp}$. 691.596,97.

3. pembelian mentega yang optimal adalah 168,41 Kg. Dengan frekuensi pembelian 21 kali, daur pesan ulang selama 12 hari dan biaya total persedian Rp. 691.135,61. Hasil tersebut dapat diartikan bahwa UD Nabila dapat melakukan pemesanan sebanyak 21 kali dalam setahun dengan kuantitas pembelian optimal sebanyak 168,41 Kg setiap kali melakukan pemesanan dengan daur pemesanan ulang selama 12 hari dan biaya total persediaan sebanyak $\mathrm{Rp}$. 691.135,61.

4. pembelian telur yang optimal adalah 83,42 $\mathrm{Kg}$. Dengan frekuensi pembelian $21 \mathrm{kali}$, daur pesan ulang selama 12 hari dan biaya total persedian Rp. 691.231,72. Hasil tersebut dapat diartikan bahwa UD Nabila dapat melakukan pemesanan sebanyak 21 kali dalam setahun dengan kuantitas pembelian optimal sebanyak $83,42 \mathrm{Kg}$ 
setiap kali melakukan pemesanan dengan daur pemesanan ulang selama 12 hari dan biaya total persediaan sebanyak Rp. 691.231,72.

\section{Persediaan Pengaman (Safety Stock)}

Persediaan pengaman sangat di perlukan dalam kegiatan produksi suatu usaha. Persediaan pengaman dilakukan untuk mencegah terjadinya kekurangan bahan baku dan ketidakpastian datangnya bahan baku yang dapat menyebabkan produksi perusahaan terhenti. Jumlah persediaan pengaman dapat dihitung dengan cara membandingkan antara jumlah pembelian bahan baku dengan rata-rata pembelian bahan baku kemudian dicari standar deviasi dari bahan baku tersebut. Dalam analisis penyimpangan ini manajemen perusahaan menentukan seberapa jauh bahan baku yang masih dapat diterima, Pada umumnya batas toleransi yang digunakan adalah $5 \%$ diatas perkiraan dan $5 \%$ dibawah perkiraan dengan nilai 1,65 (Ruauw, 2011).

Jadi dari hasil perhitungan pada lampiran dapat diketahui persediaan pengaman yang harus disediakan oleh UD roti Nabila adalah :

a. Bahan baku tepung sebesar $124,17 \mathrm{Kg}$

b. Bahan baku gula sebesar $33,28 \mathrm{Kg}$

c. Bahan baku mentega sebesar $23,33 \mathrm{Kg}$

d. Bahan baku telur sebesar $16,58 \mathrm{Kg}$

Saat bahan baku yang dipesan tiba dalam jangka waktu 7 hari, bahan baku yang tersisa sesuai dengan hasil perhitungan yang ada di atas.

\section{Penentuan Pemesanan Kembali (Reorder Point)}

Reorder Point adalah keadaan dimana suatu usaha melakukan pemesanan bahan baku kembali. tujuan dari pemesanan kembali adalah agar bahan baku tiba tepat pada saat persediaan bahan baku yang ada habis. UD roti Nabila dalam melakukan pemesanan bahan baku memiliki waktu tunggu (lead time) selama 7 hari dan memiliki hari kerja sebanyak 240 hari.

Berdasarkan hasil perhitungan pada lampiran 7 menunjukan bahwa UD Nabila dapat melakukan pemesanan kembali bahan baku pada saat bahan baku yang tersisa sebesar

1. $974,39 \mathrm{Kg}$ untuk bahan baku tepung

2. $202,54 \mathrm{Kg}$ untuk bahan baku gula
3. $125,18 \mathrm{Kg}$ untuk bahan baku mentega

4. $66,98 \mathrm{Kg}$ untuk bahan baku telur

Agar bahan baku yang diperlukan tetap tersedia dan proses produksi dapat berjalan dengan lancar.

\section{Persediaan Maksimum (Maximum Inventory) \\ Persediaan Maksimum (Maximum} Inventory) adalah persediaan yang dilakukan oleh suatu usaha, agar tidak terjadi kelebihan bahan baku,yang dapat menyebabkan terjadinya pemborosan biaya.

Berdasarkan hasil perhitungan pada lampiran 8 menunjukkan bahwa persediaan maximum untuk masing-masing bahan baku adalah :

1. Bahan baku tepung sebesar $1.527,61 \mathrm{Kg}$

2. Bahan baku gula sebesar $313,04 \mathrm{Kg}$

3. Bahan baku mentega sebesar $191,75 \mathrm{Kg}$

4. Bahan baku telur sebesar $100 \mathrm{Kg}$

Agar tidak terjadi pemborosan biaya, sebaiknya UD Nabila melakukan pembelian bahan baku tidak melebihi hasil maximum inventori yang telah dihitung.

Tabel 3 menunjukan lebih jelas tentang perhitungan persediaan bahan baku (EOQ, safety stock, reorder point, maximum inventory dan biaya total persediaan) setiap kali melakukan pemesanan pada UD Nabila tahun 2015.

\section{Biaya Total Persediaan Yang Dikeluarkan UD Nabila}

Perhitungan biaya total persediaan yang dikeluarkan oleh UD Nabila akan dihitung dengan menggunakan rumus sebagai berikut :

TIC $=$ (Penggunaan Rata-rata $)(\mathrm{H})+$ (P) (S) (F)

Jadi biaya total persediaan yang dikeluarkan UD Nabila untuk masing-masing bahan baku adalah :

1. Bahan baku tepung sebesar Rp. 1.548.510,02

2. Bahan baku gula sebesar Rp. $1.545 .769,88$

3. Bahan baku mentega sebesar Rp. 1.544.170,95

4. Bahan baku telur sebesar Rp. 1.544.530,69

Dapat di lihat bahwa biaya total persediaan UD Nabila lebih besar, bila dibandingkan dengan biaya total persediaan dengan menggunakan metode EOQ. 
Tabel 3. Besarnya EOQ, Safety Stock, Reorder Point, Maximum Inventory dan Biaya Total Persediaan Persediaan Setiap Kali Melakukan Pemesanan pada Tahun 2015

\begin{tabular}{lrrrrr}
\hline $\begin{array}{l}\text { Bahan } \\
\text { Baku }\end{array}$ & EOQ $(\mathrm{Kg})$ & $\begin{array}{c}\text { Safety Stock } \\
(\mathrm{Kg})\end{array}$ & $\begin{array}{c}\text { Reorder } \\
\text { Point }(\mathrm{Kg})\end{array}$ & $\begin{array}{c}\text { Maximum } \\
\text { Inventory }(\mathrm{Kg})\end{array}$ & $\begin{array}{c}\text { Biaya Total } \\
\text { Persediaan }(\mathrm{Rp})\end{array}$ \\
\hline Tepung & $1.403,44$ & 124,17 & 974,39 & $1.527,61$ & $692.390,59$ \\
Gula & 279,76 & 33,28 & 202,54 & 313,04 & $691.596,97$ \\
Mentega & 168,41 & 23,33 & 125,18 & 191,74 & $691.135,61$ \\
Telur & 83,42 & 16,58 & 66,98 & 100 & $691.231,72$ \\
\hline
\end{tabular}

Sumber: Data Primer (diolah),2016

Tabel 4. Biaya Total Persediaan Menurut UD Nabila dan Biaya Total Persediaan Menurut Metode EOQ (Economic Order quantity)

\begin{tabular}{lrr}
\hline \multicolumn{1}{c}{ Bahan Baku } & BTP menurut UD Nabila (Rp) & $\begin{array}{c}\text { BTP menurut metode EOQ } \\
(\text { Rp) }\end{array}$ \\
\hline Tepung & $1.548 .510,02$ & $692.390,59$ \\
Gula & $1.545 .769,88$ & $691.596,97$ \\
Mentega & $1.544 .170,95$ & $691.135,61$ \\
Telur & $1.544 .530,69$ & $691.231,72$ \\
\hline
\end{tabular}

Sumber: Data Primer (diolah),2016

Tabel 4 menunjukan dengan menggunakan metode EOQ, UD Nabila terjadi penghematan total biaya persediaan, di mana total biaya persediaan dengan metode EOQ lebih kecil di bandingkan dengan biaya total persediaan yang dilakukan UD Nabila.

\section{KESIMPULAN DAN SARAN}

\section{KESIMPULAN}

Berdasarkan hasil penelitian yang dilaksanakan di UD Nabila, dapat disimpulkan bahwa dalam menetapkan pembelian bahan baku, UD Nabila belum mempunyai manajemen persediaan bahan baku yang baik. UD Nabila belum dapat memperhitungkan pembelian bahan baku yang optimal, dimana pembelian bahan baku UD Nabila lebih besar dibandingkan dengan penggunaan bahan baku sehingga menyebabkan terjadinya pemborosan biaya. Dari hasil perhitungan dengan menggunakan metode EOQ, UD Nabila dapat mengetahui jumlah pembelian bahan baku optimal yang harus disediakan sehingga UD-
Nabila tidak terjadi pemborosan biaya dan tidak terjadi kekurangan bahan baku, serta UD Nabila dapat menekan pemborosan biaya yang telah terjadi selama menjalankan usaha, dimana dapat dilihat dari hasil perhitungan, biaya total persediaan UD Nabila lebih besar bila dibandingkan dengan biaya total persediaan dengan metode EOQ.

\section{SARAN}

Dalam melaksanakan usaha UD Nabila sebaiknya menggunakan metode EOQ. Dengan metode EOQ UD Nabila dapat melakukan pembelian bahan baku dalam jumlah yang optimal dan menekan biaya persediaan yang berlebihan, sehingga proses kegiatan produksi dapat berjalan secara baik dan teratur.

UD Nabila dalam pengadaan bahan baku sebaiknya melakukan pembelian sesuai dengan maximum inventory yang telah dihitung agar tidak terjadi kekurangan bahan baku dan mengurangi pemborosan biaya. 


\section{DAFTAR PUSTAKA}

Assauri, S., 2014. Manajemen Pemasaran. Rajawali Pers, 2014.

Djakarta, D, I., 2012. Pengaruh Marketing mix Terhadap Keputusan Pembelian (Studi Pada Indonesia Seller Perusahaan E-Commerce eBay). Fakultas Ekonomi dan Bisnis Universitas Diponegoro, Semarang.

Handoko, T,H., 2015. Dasar-Dasar Manajemen Produksi dan Operasi. BPFE, Yogyakarta.

Herjanto, E., 2008. Manajemen Operasi Edisi 3. Grasindo, Jakarta.

Lestari, R.W., 2010. Analisis Pengaruh Usaha Kecil Dan Menengah (UKM) Gabungan Kelompok Tani Coklat Dalam Meningkatkan Pendapatan Masyarakat (Studi Kasus di Kecamatan Kademangan, Kabupaten Blitar, Fakultas Tarbiyah Universitas Islam Negri, Malang.

Nur'Aini, A., 2011. Aplikasi Millet (Pennisetum spp) Merah dan Millet Kuning Sebagai Substitusi Terigu Dalam Pembuatan Roti Tawar: Evaluasi Sifat Sensoris Dan Fisikokimia, Fakultas Pertanian Universitas Sebelas Maret, Surakarta.

Pamungkas dan Sutanto. Analisis Pengendalian Bahan Baku Menggunakan Metode EOQ (Economic Order Quantity) Studi Kasus Pada PT Misajaya Mitra CO.LTD, Jurnal Universitas Ahmad Dahlan.

Presiden Republik Indonesia., 1995. UndangUndang No.9 Tahun 1995 Tentang: Usaha Kecil. LN 74; TN 3611.

Respatiningsih, H. 2011. Manajemen Kredit Usaha Mikro Kecil Dan Menengah (UMKM) No 1. Jurnal Manajemen dan Bisnis.
Ruauw, 2011. Pengendalian Persediaan Bahan Baku (Contoh Pengendalian Pada Usaha Grenda Bakery Lianli, Manado), Jurnal Volume 7 Nomor 1, Manado.

Sari, S. P., 2010. Pengoptimalan Persediaan Bahan Baku Kacang Tanah Menggunakan Metode EOQ (Economic Order Quantity) Di PT. Dua Kelinci Pati, Fakultas Pertanian Universitas Sebelas Maret, Surakarta.

Soekartawi, 2005. Agribisnis Teori Dan Aplikasinya, PT RajaGrafibdo Persada, Jakarta

Syamsuddin, L., 2004 Manajemen Keuangan Perusahaan Konsep Alpikasi Dalam Perencanaan, Pengawasan, dan Pengambilan Keputusan, PT Raja Grafindo Persada, Jakarta.

Tampobulon, 2004. Pengendalian Persediaan Bahan Baku Di PT. Karya Murni Perkasa, Skripsi Fakultas Ekonomi Universitas HKBP Nommensen, Medan.

Taryana, 2008. Analisis Pengendalian Persediaan Bahan Baku Pada Produk Sepatu Dengan Pendekatan Teknik Lot Sizing Dalam Mendukung Sistem MRP (studi kasus di PT. Sepatu Mas Idaman), Skripsi Fakultas Teknologi Pertanian Institut Pertanian, Bogor.

Tatuh D, 2015. Analisis Pengelolaan Persediaan Beras PT.Semarak Kota Bitung, Skripsi Fakultas Pertanian Universitas Sam Ratulangi, Manado.

Winoto S. S., 2008. Analisis Efisiensi Pengendalian Persediaan Bahan Baku Teh Di PT. Rumpun Sari Kemuning I Karanganyar, Skripsi Fakultas Pertanian Universitas Sebelas Maret, Surakarta.

Yamit, J., 2007. Manajemen Kuantitatif Untuk Bisnis (Operation Reseacrch). BPFE, Yogyakarta. 